\title{
Fracture-related infection
}

\section{S. Baertl, W-J. Metsemakers, M. Morgenstern, V. Alt, \\ R. G. Richards, T. F. Moriarty, K. Young}

From $A O$ Research Institute Davos, Davos, Switzerland

Correspondence should be sent to Thomas Fintan Moriarty; email: fintan.moriarty@aofoundation.org doi: 10.1302/2046-3758.106.BJR2021-0167.R1

Bone Joint Res 2021;10(6):351353.

Cite this article: Bone Joint Res 2021;10(6):351-353.

Keywords: Infection, Fracture, Trauma

\section{Background}

Fracture-related infection (FRI) carries a substantial burden of disease and socioeconomic costs. ${ }^{1-3}$ The incidence of FRI is $1 \%$ to $2 \%$ in closed fractures and can reach $30 \%$ in open fractures. ${ }^{1}$ Until recently, amputation and recurrence rates remained high. ${ }^{2,4}$ With the publication of international consensus documents, ${ }^{4,5}$ an evidence-based overview of diagnosis and management has been provided, which should improve treatment outcomes.

\section{Pathology}

The pathology of FRI is multifactorial; bacterial infection and fracture instability are interdependent and fundamental in FRI. ${ }^{6,7}$ Biofilm formation, canalicular invasion, ${ }^{8}$ intracellular infection, ${ }^{9}$ and formation of staphylococcal abscess communities ${ }^{10}$ are the key niches occupied by bacteria. A vicious cycle between instability with ongoing soft-tissue trauma, compromised neovascularity, and osteolysis creates a supportive environment for bacteria, promoting the development of FRI or hindering its eradication. ${ }^{6}$

\section{Diagnosis}

Confirmatory criteria include fistula or sinus tract, purulent drainage or pus, microbial growth in two or more deep tissue samples, and histological evidence of pathogens and inflammation in peri-implant tissue. ${ }^{4,5}$ Suggestive criteria include clinical signs such as: erythema; swelling; persistent, increasing, or new-onset wound drainage; radiological or nuclear imaging signs; increased serum inflammatory markers; and microbial growth in a single deep tissue sample. ${ }^{5,7}$

\section{Management}

A consensus-derived management algorithm has been developed and should be led by a multidisciplinary team. ${ }^{5,7}$ Based on three basic principles, consisting of exchange, retention, or removal of the indwelling implant, the preferred strategy depends on host physiology, time interval between fracture fixation and FRI manifestation, anatomical localization, and causative pathogen. For implant retention, the stability of the construct and the ability to perform proper debridement are critical, considering the implant type and softtissue conditions. $^{7}$

\section{Prevention}

Appropriate use of prophylactic antibiotics is crucial to prevent FRI. In closed injuries, perioperative antibiotic prophylaxis limited to a single dose is recommended. In open fractures, prophylactic antibiotic administration should not exceed 24 hours for Gustilo-Anderson types I and II and 72 hours for Gustilo-Anderson type III fractures. ${ }^{5,7}$ Early debridement, soft-tissue management, and stable fracture fixation are cornerstones of management. ${ }^{5}$

Follow-up of FRI should be planned in collaboration with a multidisciplinary team, for a minimum of 12 months after the cessation of surgical and antibiotic therapy. ${ }^{11}$

Future perspectives for prevention and management of FRI include: antimicrobial coated implants; osteoinductive antibioticloaded biomaterials; and bacteriophage and enzybiotic therapy. All these therapies consider the global threat of antibiotic resistance and target mechanisms of antimicrobial tolerance such as biofilm formation. 


\section{Fracture-Related Infection}
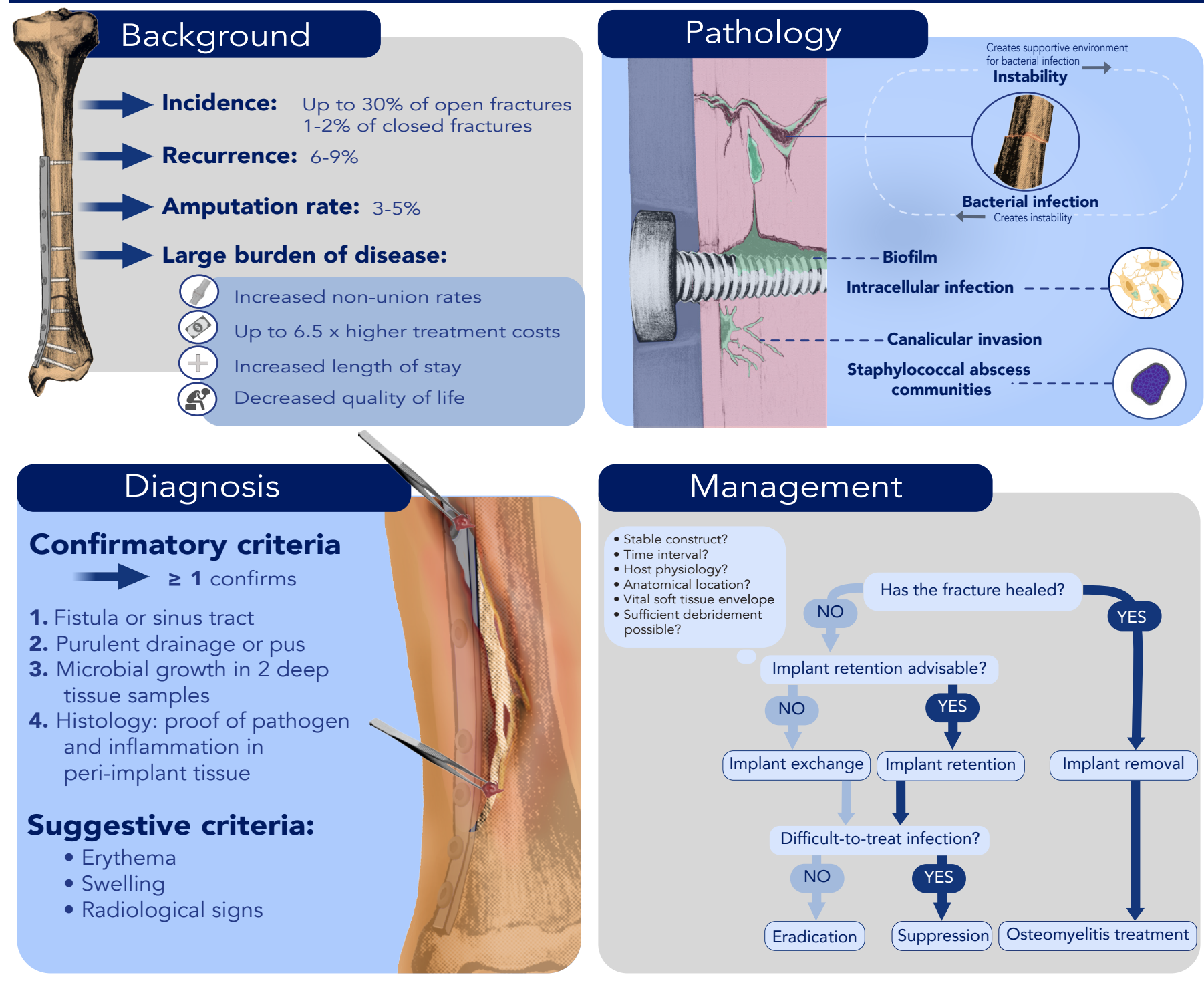

\section{Prevention}

\section{Closed fractures}

- Perioperative antibiotics

- Soft-tissue care

- Early stable fixation

\section{Open fractures}

Orthoplastic care:

Early stable fixation and timely soft-tissue coverage

Antibiotic prophylaxis

- GA type I/II 24 hours

- GA type III 72 hours

\section{Follow-up}

Minimum 12 months follow-up after cessation of surgical and antibiotic therapy

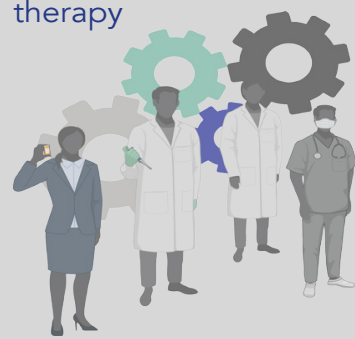

\section{Multidisciplinary team approach}

\section{Future Perspectives}

Osteoinductive antibiotic loaded biomaterials
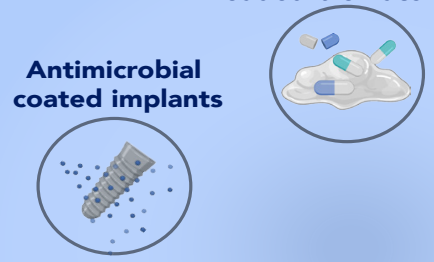

Bacteriophage therapy
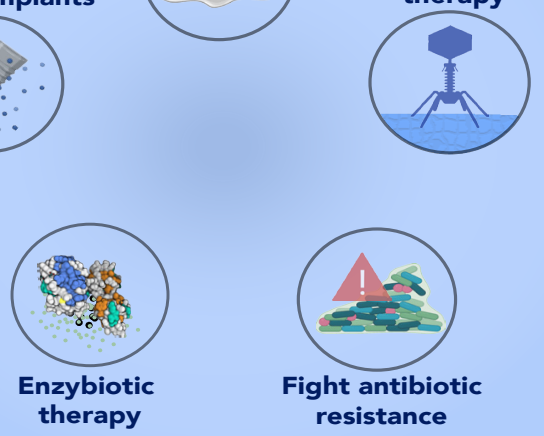

Fight antibiotic resistance 
Twitter

Follow T. F. Moriarty @fintan_moriarty

\section{References}

1. Metsemakers WJ, KuehI R, Moriarty TF, et al. Infection after fracture fixation: Current surgical and microbiological concepts. Injury. 2018;49(3):511-522.

2. Metsemakers W-. J, Smeets B, Nijs S, Hoekstra H. Infection after fracture fixation of the tibia: Analysis of healthcare utilization and related costs. Injury 2017:48(6):1204-1210.

3. Bezstarosti H, Van Lieshout EMM, Voskamp LW, et al. Insights into treatmen and outcome of fracture-related infection: A systematic literature review. Arch Orthop Trauma Surg. 2019;139(1):61-72.

4. Metsemakers WJ, Morgenstern M, McNally MA, et al. Fracture-related infection: A consensus on definition from an international expert group. Injury. 2018:49(3):505-510

5. Obremskey WT, Metsemakers W-J, Schlatterer DR, et al. Musculoskeletal infection in orthopaedic trauma: Assessment of the 2018 international consensus meeting on musculoskeletal infection. J Bone Joint Surg Am. 2020;102-A(10):e44.

6. Foster AL, Moriarty TF, Zalavras C, Morgenstern M, Jaiprakash A, Crawford R. The influence of biomechanical stability on bone healing and fracture-related infection: the legacy of Stephan Perren. Injury. 2020;52(1):43-52.

7. Depypere M, Morgenstern M, KuehI R, Senneville E, Moriarty TF, Obremskey WT. Pathogenesis and management of fracture-related infection. Clin Microbiol Infect. 2020;26(5):572-578.

8. de Mesy Bentley KL, Trombetta R, Nishitani K, et al. Evidence of staphylococcus aureus deformation, proliferation, and migration in canaliculi of live cortical bone in murine models of osteomyelitis. J Bone Miner Res. 2017;32(5):985-990.

9. Mohamed W, Sommer U, Sethi S, Domann E, Thormann U, Schütz I. Intracellular proliferation of $\mathrm{S}$. aureus in osteoblasts and effects of rifampicin and gentamicin on $\mathrm{S}$ aureus intracellular proliferation and survival. Eur Cell Mater. 2014;28:258-268.

10. Hofstee MI, Riool M, Terjajevs I, et al. Three-Dimensional In Vitro Staphylococcus aureus Abscess Communities Display Antibiotic Tolerance and Protection from Neutrophil Clearance. Infect Immun. 2020;88(11):e00293-20.
11. Metsemakers W-J, Morgenstern M, Senneville E, et al. General treatment principles for fracture-related infection: Recommendations from an international expert group. Arch Orthop Trauma Surg. 2020;140(8):1013-1027.

Author information

- S. Baertl, MD, Orthopaedic Trauma Surgeon, AO Research Institute Davos, Davos, Switzerland; Department of Trauma Surgery, University Medical Center Regensburg, Regensburg, Germany.

W-J. Metsemakers, MD, Orthopaedic Trauma Surgeon, Department of Trauma Surgery, University Hospitals Leuven, Leuven, Belgium.

M. Morgenstern, MD, Orthopaedic Trauma Surgeon, Center for Musculoskeletal Infections, University Hospital Basel, Basel, Switzerland.

V. Alt, MD, Professor, Chairman, and Director, Department of Trauma Surgery, University Medical Center Regensburg, Regensburg, Germany.

R. G. Richards, PhD, Director

II. F. Moriarty, PhD, Principal Scientist

K. Young, MD, Orthopaedic Trauma Surgeon

AO Research Institute Davos, Davos, Switzerland.

Author contributions:

S. Baertl: Designed, created, and revised the infographic

W-J. Metsemakers: Designed and revised the infographic.

M. Morgenstern: Designed and revised the infographic.

V. Alt: Designed and revised the infographic.

R. G. Richards: Revised the infographic

T. F. Moriarty: Conceptualized, designed, and revised the infographic.

K. Young: Designed and revised the infographic.

Funding statement:

No benefits in any form have been received or will be received from a commercial party related directly or indirectly to the subject of this article.

Acknowledgements:

We acknowledge the contribution of Medical Artist Louise Hinman in preparing the illustrations for this infographic.

(c) 2021 Author(s) et al. This is an open-access article distributed under the terms of the Creative Commons Attribution Non-Commercial No Derivatives (CC BY-NC-ND 4.0) licence, which permits the copying and redistribution of the work only, and provided the original author and source are credited. See https://creativecommons.org/licenses/ by-nc-nd/4.0/. 